ный аграрный университет имени Н.И. Вавилова. Россия.

Павлов Андрей Владимирович, канд. техн. наук, дочент кафедры «Технический сервис и технология конструкиионных материалов», Саратовский государственный аграрный университет имени Н.И. Вавилова. Россия.

Нестеров Евгений Сергеевич, канд. техн. наук, доиент кафедры «Проиессы и сельскохозяйственные машины в АПК», Саратовский государственный аграрный университет имени Н.И. Вавилова. Россия.
Лаврентьев Алексей Васильевич, аспирант кафедры «Процессы и сельскохозяйственные машины в АПК», Саратовский государственный аграрный университет имени Н.И. Вавилова. Россия.

410056, г. Саратов, ул. Советская, 60.

Тел.: (8452) 73-64-12.

Ключевые слова: пахотный агрегат; трактор; прицепной плуг; крюковое усилие; скорость движения; глубина обработки почвы; производительность.

\title{
RATIONAL COMBINING OF A TRAILED PLASTER WITH FOREIGN TRACTORS
}

Boykov Vasiliy Mihaylovich, Doctor of Technical Sciences, Professor of the chair "Processes and Agricultural Machinery in AIC", Saratov State Agrarian University named after N.I. Vavilov. Russia.

Startsev Sergey Viktorovich, Doctor of Technical Sciences, Professor of the chair "Processes and Agricultural Machinery in APIC", Saratov State Agrarian University named after N.I. Vavilov. Russia.

Pavlov Andrey Vladimirovich, Candidate of Technical Sciences, Associate Professor of the chair "Technical Service and Technology of Structural Materials", Saratov State Agrarian University named after N.I. Vavilov. Russia.

Nesterov Evgeniy Sergeevich, Candidate of Technical Sciences, Associate Professor of the chair "Processes and Agricultural Machinery in AIC", Saratov State Agrarian University named after N.I. Vavilov. Russia.

Lavrentyev Aleksey Vasilyevich, Post-graduate Student of the chair "Processes and Agricultural Machinery in AIC", Saratov State Agrarian University named after N.I. Vavilov. Russia.

Keywords: arable unit; tractor; trailed plow; hook force; speed; depth of tillage; productivity.
Using the technical characteristics of the PBS-10P trailed plow and plow and the results of the PBS series plow tests at the Povolzhskaya machine test station, the results of the tractor tests by the Nebraska Tractor Test USA laboratory established the hook force of the tractors John Deer $9120(196 k W)$, New Holland $9282(175 k W)$, Versatile 375 (268kW), Case Magnum 340 (251kW), Challenger MT 835 (267kW), Fendt 926 (200kW), Massey Fergusson $8480(200 \mathrm{~kW})$ and traction resistance of the trailing plow PBS-10P at the corresponding speeds, hook force tra and the traction resistance of the plow from the speed of movement. The optimum operational parameters of the completed arable aggregates were determined by graphoanalytical method and their theoretical comparative estimation on productivity on the basic soil cultivation in different conditions is given. The results of experimental investigations of the Case Magnum $340+$ PBS-10P arable aggregate in the conditions of the economy of the Saratov region are presented and the convergence of the theoretical and experimental studies obtained is checked.

\section{ХАРАКТЕРИСТИКА ПОСЛЕДСТВИЙ НЕНОРМИРУЕМЫХ УСЛОВИЙ ТРУДА В РАЗЛИЧНЫХ ПРОИЗВОДСТВАХ ЭНЕРГЕТИЧЕСКОГО ОБЕСПЕЧЕНИЯ И ПУТИ ИХ УЛУЧШЕНИЯ}

\author{
оРЛОВ Павел Сергеевич, Ярославская государственная сельскохозяйственная академия \\ ШКРАБАК Владимир Степанович, Санкт-Петербургский государственный аграрный \\ университет
}

ГОЛдОБИНА Любовь Александровна, Санкт-Петербургский горный университет СОЦКАЯ Ирина Марковна, Ярославская государственная сельскохозяйственная академия ШКРАБАК Роман Владимирович, Санкт-Петербургский государственный аграрный университет

Приведена характеристика последствий ненормируемых условий труда в различных производствах энергетического обеспечения предприятий и путей их улучшения. Обращено внимание на производственный травматизм и профессиональную заболеваемость. Даны краткие сведения о предложенных авторами решениях в части повышения эффективности и безопасности электроснабжения потребителей. Приведены результаты экспериментальных исследований предложенных рещений.

Введение. Общеизвестно, что условия труда определяющим образом влияют на уровень травматизма, профессиональной и производственно обусловленной заболеваемости работников всех видов экономической деятельности, включая агропромышленный комплекс (АПК).
Разнообразные виды производства и жизнедеятельности в целом генерируют свои вредности и опасности, которые в ряде случаев приводят к травмам и заболеваниям, к авариям, взрывам, чрезвычайным ситуациям. Характеризуя вредности отметим, что они сгруппированы, 
как и опасности, системой стандартов безопасности труда [3], имеют свою классификацию, предельно допустимые уровни, концентрации, значения, дозы, нормы. Эти значения нормированы для основных источников вредностей и опасностей на основе больших научно-исследовательских и практических работ и широко известны специалистам и работающим.

Отметим также, что в ряде случаев установленные требования по обеспечению нормируемых условий труда не выполняются в полной мере с различными последствиями для здоровья и жизни работников.

Методика исследований. В связи с большим разнообразием видов экономической деятельности проведем анализ некоторых из них, имеющих отношение к проблеме в целом, касаясь условий труда и их последствий в интегрированных производствах, результаты которых используются в разных видах экономической деятельности. При этом основное внимание будет уделено надежности видам работ с точки зрения эффективности производства и охраны труда.

В Российской Федерации при решении вопросов охраны труда традиционно большое внимание уделяется основному направлению работодателей и специалистов охраны труда предприятий - профилактике несчастных случаев на производстве. В то же время профессиональные заболевания в большинстве случаев являются причиной утраты трудоспособности, от которых ежегодно погибает в 6 раз больше работников, чем от несчастных случаев.

Профессиональные заболевания возникают в результате воздействия на работников факторов риска, но для того, чтобы признать заболевание именно профессиональным, необходимо доказать причинно-следственную связь между полученным заболеванием и воздействием на работника опасного фактора. В то же время характер профессиональных заболеваний постоянно и быстро меняется; технический прогресс и социальные перемены в сочетании с глобальными экономическими условиями усугубляют существующие угрозы здоровью, вызывая новые профессиональные болезни, как, например, психические расстройства и повреждения опорнодвигательного аппарата.

Результаты исследований. По оценкам МОТ, ежегодно от несчастных случаев на производстве и от профзаболеваний гибнет 2,34 млн чел.; 2,02 из них - в результате профзаболеваний. Из 6300 ежедневно гибнущих на работе 5500 погибают в результате профессиональных заболеваний, а число случаев профессиональных заболеваний, не приводящих к смерти, составляет 160 млн в год.

В экономике России около 49 млн рабочих мест, на которых занято около 75 млн работ- ников. Численность работников, занятых во вредных условиях труда, высока и составляла в 2008 г. $-26,2 \%$, в 2009 г. $-27,5$, в 2010 г. -29 , в 2011 г. - 30,5, в 2012 г. - 31,8 \% соответственно.

Число рабочих мест с вредными условиями труда в 2012 г. В обрабатывающей промышленности составляло 33,4 \%; на транспорте $35,6 \%$; в горнодобывающей промышленности $46,2 \%$, в других отраслях производства она ниже на 2,0-2,5 \%, осредненно составляя начало 2017 г. 37,5 \%. В то же время на предприятиях сельского хозяйства, охоты и лесного хозяйства (по данным Росстата) удельный вес занятых во вредных и (или) опасных условиях труда составил на этот же период 38,2 \%. Последствиями этого являлись профзаболевания 109 чел. (из 4149 чел. в стране).

В 2010-2012 гг. в РФ зарегистрировано 25410 случаев профзаболеваний. По данным Роспотребнадзора, в 2011 г. показатель профессиональной заболеваемости в РФ составил 1,92 заболевания на 10000 работников.

Всего в РФ вследствие неудовлетворительного состояния условий и охраны труда страна потери составляют 1,94 трлн руб. - 4,3 \% ВВП (159 млрд руб. - из фонда социального страхования; 300 млрд руб. - пенсионный фонд; 1,48 трлн руб. - потери фонда рабочего времени вследствие травматизма).

В сложном положении оказались сельскохозяйственные работники и работники малых предприятий, представляющие подавляющее большинство рабочей силы, так как они находятся вне сферы действия систем, обеспечивающих профилактику, учет профессиональных заболеваний и осуществляющих выплаты социальных пособий [5].

Следует отметить трубопроводный транспорт, занимающий лидирующее положение по грузообороту в Российской Федерации, и сравнительно низкий травматизм работников отрасли, на который с 1990 по 2010 г. приходилась почти половина грузооборота (табл. 1) [2].

Основными грузами магистрального трубопроводного транспорта России являются нефть, нефтепродукты и природный газ. В начале 2010-х гг. их грузооборот и перекачка магистральными трубопроводами были примерно равны. Так, еще в 1970 г. доля перекачки нефти трубопроводами составляла $51 \%$, в 1995 г. - 62-63\%, в 2010 г. - 66-67 \%. Однако дореформенные объемы поставки нефтепродуктов пока на рассматриваемое время были не достигнуты (табл. 2) [2].

В целом на магистральном трубопроводном транспорте, осуществляющем транспортирование нефти и нефтепродуктов, после аварий в 1993-1998 гг. удельная аварийность постоянно снижалась (табл. 3) и в начале 2010-х гг. вышла на уровень 1900-х гг. [2]. 
Грузооборот РФ (до 1990 г. без газопроводного транспорта)

\begin{tabular}{|c|c|c|c|c|c|c|c|c|c|c|}
\hline \multirow{2}{*}{ Транспорт } & \multicolumn{10}{|c|}{ Удельный вес грузооборота, \% } \\
\hline & 1970 & 1980 & 1990 & 1995 & 2000 & 2005 & 2010 & 2012 & 2013 & 2014 \\
\hline Железнодорожный & 64,10 & 52,50 & 41,20 & 32,90 & 37,70 & 39,70 & 42.30 & 43.90 & 43,20 & 45,30 \\
\hline Автомобильный & 4.40 & 5,50 & 4,90 & 4,20 & 4,20 & 4,10 & 4,20 & 4,90 & 4,90 & 4,90 \\
\hline Трубопроводный & 9,30 & 24,70 & 421,10 & 51,50 & 52,70 & 52,90 & 50.10 & 48,50 & 49,40 & 47.70 \\
\hline Морской & 15,80 & 12,10 & 8.30 & 8,80 & 3,40 & 1,30 & 2,10 & 0,90 & 0,80 & 0,60 \\
\hline Речной & 6,30 & 5.20 & 3.50 & 2.50 & 2,00 & 1,90 & 1,10 & 1,60 & 1,60 & 1,40 \\
\hline Воздушный & & 0,05 & 0,04 & 0,07 & 0,07 & 0,06 & 0,10 & 0,10 & 0,10 & 0,10 \\
\hline
\end{tabular}

Таблица 2

Транспорт нефтепродуктов в РФ

\begin{tabular}{|c|c|c|c|c|c|c|c|c|c|c|}
\hline \multirow{2}{*}{ Транспорт } & \multicolumn{10}{|c|}{ Транспорт нефтепродуктов в РФ, млн т } \\
\hline & 1960 & 1970 & 1980 & 1990 & 2000 & 2005 & 2010 & 2011 & 2013 & 2014 \\
\hline Железнодорожный & 118,0 & 219,0 & 279,0 & 247,0 & 155,0 & 219,0 & 253,0 & 278,0 & 250,0 & 257,0 \\
\hline Трубопроводный & 123,0 & 303,0 & 576,0 & 558,0 & 318,0 & 482,0 & 525,0 & 576,0 & 558,0 & 556,0 \\
\hline Морской & & 37,0 & 54,0 & 53,0 & 10,0 & 3,6 & 6,5 & 6,1 & 7,1 & \\
\hline Речной & 18,0 & 32,0 & 40,0 & 33,0 & 1200 & 17,0 & 13,0 & 15,0 & 17,0 & \\
\hline Всего & 259,0 & 591,0 & 949.0 & 891,0 & 495.0 & 721,6 & 797,5 & 875,1 & 832,1 & \\
\hline
\end{tabular}

Таблица 3

Аварийность на магистральном трубопроводном транспорте

\begin{tabular}{|c|c|c|c|c|c|}
\hline \multirow{2}{*}{ Год } & \multicolumn{5}{|c|}{ Аварийность на магистральном трубопроводном транспорте } \\
\cline { 2 - 6 } & Число аварий & $\begin{array}{c}\text { Длина трубопрово- } \\
\text { да, тыс. км }\end{array}$ & $\begin{array}{c}\text { Грузооборот, } \\
\text { млрд т·км }\end{array}$ & $\begin{array}{c}\text { Ущерб от аварий, } \\
\text { млн руб. }\end{array}$ & Число погибших \\
\hline 2009 & 28 & 231,0 & 2246 & 371,0 & 1 \\
\hline 2010 & 13 & 232,6 & 2382 & 146,0 & 4 \\
\hline 2011 & 17 & 237,5 & 2422 & 161,5 & 2 \\
\hline 2012 & 21 & 245,2 & 2553 & 154,8 & 0 \\
\hline 2013 & 12 & 245,8 & 1513 & 318,9 & \\
\hline 2014 & 8 & 248,1 & 2423 & 96,59 & \\
\hline
\end{tabular}

Почти 70 \% всех аварий на магистральном трубопроводном транспорте происходит на газопроводах (70 \% протяженности всех магистралей). На одну аварию регистрируется в среднем 17 инцидентов. За 2005-2014 гг. на магистральных газопроводах частота промышленных аварий достигала 1,1 аварии на 10 тыс. км, ожидаемый выброс газа составил 3,3 млн м³ газа на аварию при стоимости аварийного 1 м $^{3}$ газа 2,8-5,0 руб. (что сравнимо с ценой $1 \mathrm{~m}^{3}$ газа, отпускаемого в Подмосковье населению) [2].

Общеизвестно, что решающей составляющей современных производств является использование в них электроэнергии. Электроснабжение, его эффективность, своевременность (непрерывность) и качество определяют ритм производства и быта и играют существенную роль в стоимости продукции в целом (через стоимостную долю затраченной не это электроэнергии). Является аксиомой использование для питания электропотребителей стальных, алюминиевых, сталеалюминевых и медных проводов. Связанные с этим проблемы также общеизвестны. Так, к серьезным недостаткам медных проводов следует отнести высокую стоимость меди, ведущую к удорожанию линий электропередач, тем не менее, они нашли широкое распространение.
Одним из серьезных недостатков медных проводов является их сравнительно низкая несущая способность, ограничивающая пролет между опорами при переходах линий электропередач через водные преграды.

Нашел применение сталебронзовый провод марки БС, проводящая часть которого изготовляется из сплава БрМг 0,5. Сердечник сталебронзовых проводов скручивают из стальной оцинкованной проволоки [1].

Неустранимым недостатками сталебронзового провода являются:

наличие цинкового покрытия стального сердечника, окисляющегося с течением времени и теряющее свои защитные функции, а механический контакт между алюминием и стальным оцинкованным сердечником из-за наличия ветровой нагрузки приводит к механическому износу защитного покрытия стали, к коррозионным процессам в точках контакта стали с бронзовым сплавом, снижению несущей способности стали сердечника и надежности электроснабжения потребителей, особенно во влажном климате;

высокое электрическое сопротивление бронзовой токопроводящей жилы, даже по сравнению с алюминием, повышает потери электрической энергии на проводах. 
Авторами предложен медный провод со стальным сердечником, аналогичный по профилю сталеалюминиевому проводу. Стальная проволока сердечника предлагается алитировать за 1-3 цикла, каждый из которых состоит из операций разогрева поверхности стали до температуры $900{ }^{\circ} \mathrm{C}$ в защитной атмосфере на глубину проникновения алюминия в сталь, погружением в ванну с расплавленным алюминием и интенсивного охлаждения до температуры $550{ }^{\circ} \mathrm{C}$, а после обработки алюминиевым расплавом, находящимся под слоем расплава криолита, последующим кратковременным погружением алитированной стальной проволоки в ванну с расплавленной медью под слоем криолита для получения на поверхности стальных проволок слоя алюминиевой бронзы с медным слоем на поверхности [4].

В результате стальной сердечник обеспечивает высокую разрывную прочность провода; разогрев стальной проволоки осуществляется в защитной атмосфере на глубину диффузии алюминия, что препятствует образованию окислов железа на поверхности стали и обеспечивает заданную толщину диффузионного слоя.

Циклический разогрев поверхности стали до температуры $900{ }^{\circ} \mathrm{C}$ и последующее интенсивное ее охлаждение после обработки расплавом алюминия до температуры $550{ }^{\circ} \mathrm{C}$ обеспечивает осуществление фазовых $\alpha-\mathrm{Fe}-\gamma-\mathrm{Fe}$ и $\gamma-\mathrm{Fe}-\alpha-\mathrm{Fe}$ переходов в кратчайшие сроки и высокую производительность технологического процесса за счет ускоренного транспорта атомов алюминия в сталь в процессе фазового переноса за счет интенсификации диффузионных процессов.

Проведение от одного до трех циклов нагрева стали, обработки ее расплавом алюминия и последующее охлаждение обеспечивают необходимую концентрацию атомов алюминия в стали на заданной глубине. Наличие расплава криолита на поверхности расплавленного алюминия препятствует образованию окиси алюминия на поверхности расплава и обеспечивает высокое качество процесса алитирования стали.

Образующиеся в процессе алитирования на поверхности стали интерметаллические соединения обеспечивают плотное сцепление алюминиевого слоя со сталью и исключает отслоение алюминиевого покрытия.

Контакт разогретой стали с расплавом алюминия обеспечивает удаление следов окислов железа с алитируемой поверхности и обеспечивает высокое качество процесса. Образовавшиеся в процессе алитирования на поверхности стали интерметаллические соединения обеспечивают плотное сцепление алюминиевого слоя со сталью исключая отслоение алюминия. Алитированная сталь обеспечивает высокую прочность и коррозионную стойкость провода.

Кратковременное погружение алитированной стальной проволоки в ванну с расплавом меди, находящейся под слоем криолита обеспе- чивает получение на поверхности алитированнной стальной проволоки слоя из алюминиевой бронзы с поверхностным медным слоем, исключая контактный износ слоев повивов провода;

Алюминиевая бронза с медным слоем на поверхности алитированнной стальной проволоки обеспечивает высокую коррозионную стойкость провода и малый износ поверхностей токонесущих жил в контакте с сердечником.

Проволоки каждого последующего слоя повива наматываются в противоположную сторону намотки предыдущего, что исключает раскручивание провода при монтаже и при аварийных обрывах, облегчая производство монтажа и противоаварийных работ.

На медный провод со стальным сердечником получен приоритет [4].

Следует отметить, что предлагаемое изобретение обладает существенными недостатками, одним из которых является применение криолита, высокотемпературным являющееся фтористым соединением.

В 2018 г. авторами проведена серия экспериментов по меднению стали в расплаве буры безводной, широко применяемой в качестве флюса при пайке твердыми припоями черных металлов.

При температуре, не превышающей $1100{ }^{\circ} \mathrm{C}$, получено плотное сцепление медного слоя со стальным образцом, что открывает возможность получения медного провода со стальным сердечником без применения криолита. Применяемая в качестве флюса бура обеспечивает удаление следов окислов железа с поверхности стали, надежно очищая обрабатываемую поверхность от окислов, обеспечивая плотное и надежное сцепление медного покрытия со сталью, стальной сердечник обеспечивает высокую разрывную прочность провода, а наличие расплава буры безводной на поверхности ванны для меднения стали препятствует образованию окиси железа на поверхности стали, обеспечивая высокое качество процесса получения слоя меди на поверхности стали.

Так как проникновение меди в сталь несколько затруднено, меднение стали не снижает прочностные характеристики стального сердечника, а для осуществления процесса получения тонкого медного слоя требуется не более 15-20 мин. Время осуществления процесса определяется только мощностью нагревателя.

Расплавленная бура растворяет окислы различных металлов с образованием двойных солей металлов. На растворении окислов металлов основано применение буры при пайке металлов. Бура растворяет окислы и расплав припоя хорошо ложится на чистый металл:

$$
\begin{gathered}
\mathrm{Fe}_{2} \mathrm{O}_{3}-+3 \mathrm{Na}_{2} \mathrm{~B}_{4} \mathrm{O}_{7}=2 \mathrm{Fe}\left(\mathrm{BO}_{2}\right)_{3} \cdot 6 \mathrm{NaBO}_{2} \\
\mathrm{CuO}+\mathrm{Na}_{2} \mathrm{~B}_{4} \mathrm{O}_{7}=\mathrm{Cu}\left(\mathrm{BO}_{2}\right)_{2} \cdot 2 \mathrm{NaBO}_{2}
\end{gathered}
$$


Растворенные в расплаве буры окислы покидают поверхность стали и всплывают в виде шлаков, надежно очищая обрабатываемую поверхность от окислов, обеспечивая плотное и надежное сцепление медного покрытия со сталью и высокое качество процесса получения защитного слоя меди на поверхности стали.

Проволоки каждого последующего слоя повива наматываются в противоположную сторону намотки предыдущего, что исключает раскручивание провода при монтаже и при аварийных обрывах, облегчая производство монтажа и противоаварийных работ.

Заключение. Проведенный эксперимент подтверждает возможность получения стойкого к коррозии медного покрытия на поверхности стали и может использоваться для защиты поверхности стальных сердечников электрических медных проводов от коррозии и стальных труб от коррозии и от КРН, так как предлагаемые медные покрытия обладают высокой стойкостью к коррозии и защищают сталь от наводороживания. Предлагаемая технология упрощает технологический процесс нанесения защитного покрытия на сталь, уменьшает число необходимых операций по нанесению высокостойких к коррозии покрытий и снижает вероятность образования аварийных ситуаций как на линиях электроснабжения, так и на подземных трубопроводах, снижая профессиональные риски как работников эксплуатирующих организаций так и работников сельского хозяйства, по территориям которых проходят трассы трубопроводов и линий электропередач.

\section{СПИСОК ЛИТЕРАТУРЫ}

1. Белоруссов Н.И. Электрические кабели и провода. - М.: Энергия, 1971.- 312 с.

2. Голдобина Л.А., Шкрабак В.С., Орлов П.С. Предупреждение аварий и катастроф на катоднозащищенных подземных трубопроводах бесконтактными методами идентификации коррозионного разрушения. - СПб.; Ярославл, 2012. - 202 с.

3. Система стандартов безопасности труда (ССБТ). - Режим доступа: http://docs.cntd.ru/ document/1200052851.

4. Соцкая И.М., Орлов П.С. Медный провод со стальным сердечником // Приоритет на патент РФ № 2016100488 от 11.01.2016 г.

5. Повышение эффективности эксплуатации энергопривода компрессорных / Б.П. Поршаков [и др.]. М.; Недра, 1992. - 207 с.

Орлов Павел Сергеевич, $\partial-p$ техн. наук, доцент, зав. кафедрой «Электрификаиия», Ярославская государственная сельскохозяйственная академия. Россия.

150042, г. Ярославль, Тутаевское шоссе, 58.

Тел.: 89159774697.

Шкрабак Владимир Степанович, $\partial-p$ техн. наук, проф. кафедры «Безопасность технологических процессов и производств», Санкт-Петербургский государственный аграрный университет. Россия.

196605, г. Санкт-Петербург - Пушкин, Петербургское шоссе, 2.

Тел.: (812) 451-76-18.

Голдобина Любовь Александровна, $\partial-p$ техн. наук, проф. кафедры «Строительные конструкции», Санкт-Петербургский горный университет. Россия.

199106, г. Санкт-Петербург, Васильевский остров, 21-я линия.

Тел.: (812) 328-86-29.

Соцкая Ирина Марковна, канд. техн. наук, доцент, зав. кафедрой «Технический сервис», Ярославская государственная сельскохозяйственная академия. Россия.

150042, г. Ярославль, Тутаевское шоссе, 58.

Тел.: 89610222526

Шкрабак Роман Владимирович, канд. техн. наук, доцент, Учебно-практический центр агротехнологий (на правах института), Санкт-Петербургский государственный аграрный университет. Россия.

196605, г. Санкт-Петербург - Пушкин, Петербургское шоссе, 2.

Тел.: (812) 451-76-18.

Ключевые слова: характеристика; последствия; труд; условия; производство; энергоснабжение; пути улучшения.

\section{THE CHARACTERISTIC OF CONSEQUENCES OF NONINFORMABLE WORKING CONDITIONS IN VARIOUS PRODUCTION OF ENERGY SECURITY AND THE WAY OF IMPROVEMENTS}

Orlov Pavel Sergeevich, Doctor of Technical Sciences, Associate Professor, Head of the chair "Electrification", Yaroslavl State Agricultural Academy. Russia.

Shkrabak Vladimir Stepanovich, Doctor of Technical Sciences, Professor of the chair "Safety of Technological Processes and Productions”, St. Petersburg State Agrarian University. Russia.

Goldobina Lyubov Alexandrovna, Doctor of Technical Sciences, Professor of the chair "Building Constructions", St. Petersburg Mining University. Russia.

Sotskaya Irina Markovna, Candidate of Technical Sciences, Associate Professor of the chair "Technical Service", Yaroslavl State Agricultural Academy. Russia.

Shkrabak Roman Vladimirovich, Candidate of Technical Sciences, Associate Professor, Educational and Practical Center of Agricultural Technology (as an institute), St. Petersburg State Agrarian University. Russia.

Keywords: characteristics; consequences; labor; conditions; production; energy supply; ways of improvement.

The characteristic of the consequences of the non-normative working conditions in various production plants of power supply of enterprises and ways of their improvement are given. Attention is paid to occupational injuries and occupational morbidity.. Brief information is provided on the solutions proposed by the authors in terms of increasing the efficiency and safety of electricity supply to consumers. The results of experimental studies of the proposed solutions are reported. 